Research Strategies, 2001, Vol. 18, No. 1 pp.29-38.

ISSN: 0734-3310

doi:10.1016/S0734-3310(02)00064-2

http://www.elsevier.com/wps/find/homepage.cws home

http://www.sciencedirect.com/science/journal/07343310

http://www.sciencedirect.com/science/article/B6W60-45H8RXK-4/2/b43f2d35f2fddb172a7eacf7426e0a10

(C) 2001Elsevier Science, Ltd. All rights reserved.

\title{
Empowering ESL students: A new model for information literacy instruction
}

\author{
Miriam E. Conteh-Morgan \\ Ohio State University Libraries, Columbus, $\mathrm{OH}$.
}

\begin{abstract}
This paper proposes a new type of collaboration between librarians and English-as-a-Second Language (ESL) instructors. Librarians will work with instructors to match similar information literacy and ESL objectives and concepts, and together build these into the ESL syllabus. However, unlike other instruction programs, the course is to be taught almost exclusively by the ESL instructor. It is believed that students will gain more from this model because it offers more learning opportunities, and stresses the cross-applicability of language and information literacy concepts and skills. Sample lesson plans are also provided. A version of this paper was presented at the OhioTESOL (an association of ESL professionals) Spring Conference, Columbus, $\mathrm{OH}$.
\end{abstract}

Empowerment is providing users with the necessary skills to find and exploit information they need for work, study and leisure. . . to help them find and develop a range of transferable skills that are essential in the Information Age. (Kirby, Liddiard, \& Moore, 1998, p. 1)

\section{Introduction}

The scenario of a librarian trying to help an international student with limited English proficiency (LEP) in an academic library is very common these days. This is hardly surprising, when one bears in mind that between 1976 and 1999, the number of international students enrolled in higher education in the United States jumped from 179,000 to 491,000 (United States Department of Commerce, 2000). Of these students currently enrolled, the overwhelming majority are nonusers of English as a primary language from Asia and Latin America.

The library experiences of these students and the librarians that serve them have been discussed in many articles. About 70 works on the academic library experience of the Englishas-a-Second Language (ESL) student spanning a period of about 25 years are listed in Moeckel and Presnell's (1995) annotated bibliography. Many of these, particularly the earlier ones, provide a cultural road map for librarians so that they will be able to serve their non-American patrons better (Greenfield, 1989; MacDonald \& Sarkodie-Mensah, 1988; Sarkodie-Mensah, 1992). Others outline various examples of collaborative bibliographic instruction, mostly instructor-requested (Cope \& Black, 1985; Feldman, 1989; Helms, 1995; Ormondroyd, 1989), or outline alternative programs given in the students' native language (Liestman \& Wu, 1990; Lopez, 1983).

In general, most institutions seem to offer broad overviews of the library, but according to Li (1998) and Nilles and Simon (1984), these may not be of much significance to international students. Moreover, some studies have shown that not many ESL students participate in these 
general orientation programs offered by libraries. For example, Allen (1993) found in her study of ESL students at the University of Illinois, that the highest number of respondents, $44.6 \%$, had never taken any of the options offered by the library: guided tours, presentations by librarians, instruction in research skills, or term paper counseling. From her findings, she extrapolates that a large number of international students in academic libraries fail to attend library instruction classes, and suggests that this could be because they are unaware of the services, "especially those which are. . aimed primarily at undergraduates"' ( p. 328). The problem could well be a failure in marketing the options to ESL students. However, it could also be that because students in ESL programs are not typically regarded as undergraduates until they "'graduate"' from language programs and embark on content-area studies. They, therefore, do not feel part of the targeted population.

Therefore, if, as these studies show, ESL students do not find general tours useful, perhaps because they tend to be more informational than instructional, and a sizeable number do not attend the generic sessions given by the library, then two questions arise. The first is what other possible alternatives should be pursued to make ESL students receive instruction in information literacy skills and become more successful library users? The other is, who else can provide instruction that they would be most likely to attend? The answers to these questions could lie outside of the library.

\section{The new model}

The teaching of information literacy ought to be integrated in the ESL curriculum to ensure that it reaches many more students with limited English skills. Course-integrated instruction, especially in basic English skills classes such as Freshman Writing, is not a new practice mainly because these classes are seen as "natural" avenues for teaching information literacy. This author believes that ESL classes are also natural avenues for integrating the teaching of information literacy. The model proposed in this article is to have librarians and instructors collaborate, especially in course development and evaluation, and assessment of learning outcomes. However, the innovative element here is that, except in a few instances (discussed later in the paper), the teaching is to be done entirely by the ESL instructor.

Some ESL professionals may question the validity of this approach given that there are professionals on campus who know the library's resources and how to use them, who are willing to help faculty and students demystify the intricacies of library use. And, likewise, some librarians will feel their role as experts is being usurped by other professionals on campus. However, as Fister (1995, p. 47) puts it, there has to be a "sense of shared ownership," primarily of knowledge, skills and constituencies, for collaboration to work well.

The assumption here is not that the proposed model is superior to those commonly used by many librarians; it is instead trying to show another approach to collaboration. The basic premises on which this model rests are: the enormous benefits students will derive from such instruction, and the belief that both bibliographic and ESL instruction share similar and overlapping theories, objectives, and practices which would make the integration of information literacy in ESL programs very easy. This article will present these arguments, outline the role both teacher and librarian will play to successfully implement the program, and give sample activities. 


\section{Rationale for new model}

\subsection{Low-anxiety environment}

ESL theories of learning and teaching practices have proved that specialized instruction creates a learning environment that is conducive to acquiring skills for academic success. One of the enabling factors is the low-anxiety environment it creates. Krashen (1981) hypothesized that in a second language-learning situation, learning is enhanced by what he calls a low "affective filter." According to his comprehensible input and affective filter hypotheses, language is learned by processing the message (input) in a low-anxiety context that acts as the affective filter in the learning process. For many students, learning information literacy skills is hardly a lowanxiety endeavor. In a study done by Mellon (1986, p. 162), it has been likened by about $75 \%$ of native English-speaking American students to "being in a foreign country and unable to speak the language."' If native speakers get library anxiety, it is not a stretch to imagine what students with LEP feel. ESL classes could provide that filter to learning information literacy skills. The students see their instructors many times a week, and normally develop a more friendly, relaxed relationship with them. These instructors are already familiar with one of the students' perceived "inadequacies" (that is, their level of communicative competence), so having them, instead of librarians, teach something that all students generally feel overwhelmed by could reduce the ESL students' anxiety.

\subsection{Student preferences}

The literature also suggests that students want specialized library instruction that incorporates ' "lots of 'hands-on,' a fair amount of illustrations, step-by-step procedures, and small student-teacher ratio, coupled with the teacher's enthusiasm, patience, warm reception, and personalized acceptance and concern for each student" (Helms, 1995, p.305). This class scenario is a facsimile description of how the majority of ESL classes are structured. In short, students do not like the instructor-dominated, lecture-demonstration format that typify library skills classes; they want to replicate the hands-on, low-anxiety, relaxed and friendly atmosphere they are familiar with, one in which they think they can learn more comfortably.

\subsection{More sustained learning}

Library instruction classes are typically the 50-min, one-session types. There is evidence in the literature (Feldman, 1989; Sarkodie-Mensah, 1994) that two-session classes are more helpful to ESL students writing research papers. Typically, these are advanced learners, and probably in the last class of the program. However, ESL teachers do assign other types of library-related exercises to students in lower levels. Beck (1990) found from her survey at Ohio University that $83 \%$ of the time elementary level instructors required students to select a book from the department's collection, and $66 \%$ of the time asked them to complete book reports. Forty-eight percent of the assignments typically given to these nonadvanced level students included reviewing a book, critiquing an article, or completing a worksheet on the process of locating books in the library. These activities show that ESL instructors are already teaching 
aspects of information literacy at all levels, within the context of language teaching. Therefore, the advantages of collaborating with librarians are threefold: to "formalize" and expand this type of instruction already taking place through librarian involvement, to sharpen ESL instructors' understanding and use of library concepts and resources so that they can teach better, and to reiterate to librarians that nonadvanced level students also need information literacy instruction to help them complete some assignments successfully.

In this new model that takes a sequenced-instruction approach, information literacy skills can be introduced earlier in lower level ESL classes, a group perhaps ignored by library instruction sessions, and be built upon in successive levels to produce even more proficient library users. The sustained learning opportunities this model affords students, as an ongoing enterprise, makes it a more viable learning alternative to the one-session, librarian-taught option.

\subsection{Shared characteristics of ESL and library instruction}

ESL teachers and librarians share common roles. ESL teachers, in their role as gatekeepers to the academic success of their students, are agents of empowerment. They pass on linguistic skills and various literacies that help prepare students for effective participation in the academic universe, and become meaningful players in a world in which the circles of English use are expanding beyond native and nativized English users (Crystal, 1997). Similarly, librarians pass on to their patrons lifelong information literacy skills. As ESL students advance into their content area studies, they are increasingly required to demonstrate good academic and information literacy skills in their papers. The common goal of librarians and ESL teachers, therefore, is to empower their constituents, in different yet complementary domains; to guide students toward self-actualization by providing the basic skills of communicating, and seeking and using appropriate information.

In addition, instruction in both fields has undergone changes in similar directions. Library instruction has seen a paradigm shift from being tools-and skills-focused to the current conceptbased model. Classes now typically focus on the bigger picture of how knowledge is organized, and on how to evaluate resources and information. The emphasis is on learning the underlying concepts and developing search strategies which will assist the patron in using a variety of information resources, instead of narrowly focusing on the use of specific tools, or tasks. Likewise, current ESL (and in general, language) pedagogy deemphasizes the skill and drill method of learning discrete aspects of language, and favors instead the global view of language as a system of communication. Learners, as the theory holds, will become more proficient communicators when they know about the language and how it functions in different academic and social contexts, an understanding that should stretch beyond performing one specific communication act. In teaching ESL writing or speech communication, for example, teachers hope their students will apply the underlying theoretical principles of language use and function, and become familiar with different rhetorical modes. Similarly, in library instruction, Bilal (1989) found that without the conceptual awareness of how to conduct library searches, it is more difficult for LEP students to understand the material presented in bibliographic instruction classes. Therefore, combining the same approach to the teaching of different, yet interconnected skills in one class could enhance the learning of both skills.

Other parallels can be constructed between the two types of instruction. Fister (1995, p. 37) argues that just as writing instruction teaches that there are different types of discourse, so too do librarians teach that "knowledge comes in distinct forms-books, articles, reference 
materials, documents.' Just as writing teachers stress the need for appropriate style and usage, librarians stress proper search strategies and relevance of resources. Both emphasize the process approach: that knowledge is constructed through a series of linear and circular movements, advancing a bit and revisiting the same steps. Inherent in this approach is the metacognitive dimension to learning; students should be aware of and reflect upon how they conduct a search or complete a language task and this makes them more sensitive to the steps they take to get a finished product. To illustrate this point further, Kuhlthau's (1995) six-step information search process mirrors the process approach to reading and writing that is so fundamental to ESL teaching. As she asserts, "[w]hen they understand the overall search process, [students] can learn specific strategies for particular stages. They begin to see that the process is experienced in a similar way each time"' (p. 51).

\section{Program requirements}

If the case has been made for the integration of library skills in ESL classes, how would this collaborative program be structured, and what would be required of both librarians and instructors? What is vital for the collaboration is that both professionals be aware of the great amount of time that will be invested in the enterprise, especially in the planning stages.

\subsection{Librarian's role}

To effectively design and implement a good program based on this model, librarians' familiarity with ESL students must go beyond the cultural tips found in many of the articles in the literature to learning more about some pertinent theories of second-language learning. Awareness of ESL theories of learning must inform the goals, objectives, and activities of the proposed course. Two that could be useful are discussed below.

One of the theories to be considered when designing such a collaborative course is that of contrastive rhetorical patterns. In his analysis of how people from different cultural groups organize information and construct meaning, Kaplan (1966) studied paragraph development in the writing of students from five cultural groups. He contrasted the linear rhetorical pattern characteristic of native English speakers with, for example, the zig-zaggy, and seemingly digressive, model of speakers of Semitic and Romance languages. He also found that some Asian cultures' styles of rhetoric begin with a small "circle", of thought, as exemplified in proverbs or parables, which slowly expands as the discourse unfolds and finally comes to the point at the end. Contrastive rhetoric does have other pedagogical implications apart from writing instruction. In library instruction, for example, knowledge of the organizational schema of different cultures, and how it influences student learning in a different language can be useful in the way information is presented and sequenced.

Another useful theory is based on how LEP students learn. Reid (1987), in her Perceptual Learning Styles Preferences study of nearly 1300 ESL students in the United States, found that the majority of students identified themselves as having a strong preference for kinesthetic and tactile learning, a conclusion also reached by the Helms survey cited earlier. Although collaborative learning was not favored highly by respondents in the Reid study, it is, however, a widely used format in ESL teaching today. Current literature shows that librarians are becoming more keenly aware of learning styles and incorporating that knowledge in their teaching (DiMartino \& Zoe, 2000). 
Second language acquisition theories may also be relevant. However, in addition to learning about pertinent ESL theories, librarians must be familiar with the goals of the ESL program on their campuses, and with the instructional objectives of the various class levels. This familiarity should help them select ESL goals and objectives and match them with the Information Literacy Competency Standards for Higher Education, the Instruction Section's Objectives for Information Literacy Instruction derived from them, or locally developed ones. The library objectives consequently adopted for the course would also have to be matched with the appropriate ESL class level so that the other collaborative effort of designing class activities and assessment tools will be made easier.

It is also expected that the librarian will teach some classes which require the demonstration of some of the skills and concepts taught by the ESL instructor. For example, following instruction on one-word or phrase summaries and connecting ideas using connectives (language objectives), and on formulating keywords and using Boolean operators (library objectives), the librarian could do a demonstration on keyword searching using Boolean logic. This could be done as part of students' preparation for assigned papers.

\subsection{ESL instructor's role}

In a corresponding manner, the ESL specialist should become more familiar with the institution's library, the terms and concepts used, and how to access and use resources. They should themselves take classes in information literacy prior to teaching it, and tap into the librarians' knowledge when they need help with or clarification of certain concepts and issues. However, of greater importance to this model is the task of matching library objectives with those of language learning as mentioned earlier. In other words, the instructor must be able to understand the concept behind the library objective so as to find a parallel language concept or objective. This time, the instructor will rely heavily on the expertise of the librarian. The benefit of such integration is that it makes the learning of a particular concept, as viewed from two different perspectives, much easier for the students. It would also help make clearer the crossapplicability of language and information literacy skills, two very crucial markers of academic success for ESL students.

The ESL instructor should also collaborate with the librarian in planning the syllabus so that they will both agree on issues such as the sequence of new topics, and when and about what the librarian should do selected demonstrations. Since instructors would be more familiar with ESL-type classroom activities, they should work with the librarian to ensure that the activities they design do teach the intended library concepts. This would also ensure that both professionals are in agreement about assessing learning outcomes. Collaboration in instructional and materials design, and in creating tools for assessing either student learning or the course as a whole, will form the bedrock of a successful ESL teacher-taught instruction program.

\subsection{Course design}

In designing a course based on this new model, building information literacy into an ESL program does not necessarily mean that the same concept in both fields has to be presented simultaneously. Introducing the concept in one area, and later using it in another teaching situation is an ideal way of stressing its transferability and of reinforcing its learning. For example, asking students to unscramble the order of sentences to create a coherent paragraph 
teaches the concept of logical organization of information. The same objective is fulfilled when later in the course they are asked to organize a shelf of books according a classification principle. Instructors should build on the students' prior knowledge in one area, and create links between both.

\section{Conclusion}

As librarians continue to strive for more successful ways to help ESL students learn information literacy skills, newer approaches to achieving this should be explored. The value of the proposed model is that it moves collaboration a step further, making it more tailor-made to the specifications of the ESL target group. It is a more effective way of reaching those who tend to shy away from library use because of language and cultural barriers. It is also effective because it grants ESL students with varying levels of English proficiency equal opportunities to learn information literacy skills.

What has been outlined here, therefore, should not be seen as turf-poaching, or as ESL teachers trying to edge out librarians. Indeed, if collaboration is to have a chance of succeeding, it will require a change of mindset: "librarians [should] give up the idea that only they can teach the basic library information skills"' (Nilles \& Simon, 1984). Using the language specialists to teach both language and information skills, both of which are necessary for this specialized group of students' academic success, can only mean the enhanced language and library skills, and ultimately, empowerment of students. This is the goal for which both ESL instructors and librarians strive.

\section{Appendix A. Sample lessons}

In these sample activities, the methodology and practices of ESL teaching are utilized. The activities can be done using dyads, triads, larger groups, or can be assigned to individual students. While the library concepts are being learned, the peer and whole-class discussions afford students opportunities for using the target language.

\section{A.1. Sample A}

Library objective: to teach the formulation of search terms.

Language objective: to teach summarizing skills.

Materials: copies of two short articles.

Activity:

- Divide class into pairs or small groups.

- Distribute copies of the articles to the groups.

- Ask students to list the key points/main ideas.

- Groups with the same article compare their lists and discuss differences.

- Have them translate those main ideas into terms they could use to search for similar articles/books (could be done later in the course).

\section{A.2. Sample B}

Library objective: to teach formulation of search terms. 
Language objective: to teach vocabulary.

Materials: index cards with various topics written down.

Activity:

- Divide class into even groups.

- Give out cards to groups, with the same topic given to two groups.

- Ask students to develop a list of concepts associated with the topic.

- Each concept must have at least two alternative forms (semantic associations, alternate spelling, politically correct terms, etc.).

- Groups with same topics share their terms with the rest of the class.

- Class discusses/modifies terms, perspectives, etc.

\section{A.3. Sample C}

Library objective: to teach how knowledge is organized.

Language objective: to teach how to organize ideas.

Materials: a list of citations (compiled by teacher or taken from a book or article; should include titles from various sources).

Activity:

- Give groups of students the list of titles.

- Ask students to organize the titles according to any principle the group decides on.

- Let each group share their final categories.

- Groups discuss their rationale for assigning titles to categories.

This same exercise can be repeated using specifically assigned organizing principles.

\section{A.4. Sample D}

Library objective: to teach the significance of boolean operators. Language objective: to teach how to combine ideas and sentences. Materials: a sample paragraph written in short, simple sentences.

Activity:

- Distribute copies of paragraph to students.

- Have students combine the sentences, paying particular attention to connecting strategies (e.g., conjunctions, subordinate clauses).

- Discuss meaning derived from using various connectives.

\section{References}

Allen, M. B. (1993). International students in academic libraries: a user survey. College and Research Libraries, 54, $323-331$.

Beck, S. E. (1990). The role of library instruction in the Ohio program of intensive English in relation to student needs. Master's thesis: Ohio University.

Bilal, D. (1989). International students' acquisition of library research skills: relationship with their English language proficiency. The Reference Librarian, 24, 129-145.

Cope, J., \& Black, E. (1985). New library orientation for international students. College Teaching, 33, 159-162.

Crystal, D. (1997). English as a global language. Cambridge: Cambridge University Press.

DiMartino, D., \& Zoe, L. R. (2000). International students and the library: new tools, new users, and new instruction. In: T. E. Jacobson, \& H. C. Williams (Eds.), Teaching the new library to today's users (pp. 17-43). New York: Neal-Schuman. 
Feldman, D. (1989). The international student and course-integrated instruction: the ESL instructor's perspective. Research Strategies, 7, 159-166.

Fister, B. (1995). Connected communities: encouraging dialogue between composition and bibliographic instruction. In: J. Sheridan (Ed.), Writing-across-the-curriculum and the academic library (pp. 35-51). Wesport, CT: Greenwood.

Greenfield, L. (1989). Training library staff to reach and teach international students. In: T. B. Mensching (Ed.), Reaching and teaching diverse library user groups (pp. 45-62). Ann Arbor: Pierian.

Helms, C. M. (1995). Reaching out to the international students through bibliographic instruction. The Reference Librarian, 50-51, 295-307.

Kaplan, R. (1966). Cultural thought patterns in intercultural education. Language Learning, 16, 1-20.

Kirby, J., Liddiard, L., \& Moore, K. (1998). Empowering the information user. London: Library Association Publishing.

Krashen, S. D. (1981). Second language acquisition and second language learning. Oxford: Pergamon.

Kuhlthau, C. (1995). The instructional role of the library media specialist in the information age. Information for a new age (pp. 47-55). Englewood, CO: Libraries.

Li, S. D. (1998). Library services to students with diverse language and cultural backgrounds. Journal of Academic Librarianship, 24, 139-143.

Liestman, D., \& Wu, C. (1990). Library orientation for international students in their native language. Research Strategies, 8, 191-196.

Lopez, M. D. (1983). Chinese spoken here: foreign language library orientation tours. College and Research Libraries News, 44, 266-268.

MacDonald, G., \& Sarkodie-Mensah, E. (1988). ESL students and American libraries. College and Research Libraries, 49, 425-431.

Mellon, C. A. (1986). Library anxiety: a grounded theory and its development. College and Research Libraries, 47, $160-165$.

Moekel, N., \& Presnell, J. (1995). A companion bibliography to: recognizing, understanding, and responding: a program model of library instruction services for international students. The Reference Librarian, 50-51, 327353.

Nilles, M. E., \& Simon, D. B. (1984). New approaches to the multilingual, multicultural students in your library. Catholic Library World, 55, 435-438.

Ormondroyd, J. (1989). The international student and course-integrated instruction: the librarian's perspective. Research Strategies, 7, 148-158.

Reid, J. M. (1987). The learning style preferences of ESL students. TESOL Quarterly, 21, 87 - 111.

Sarkodie-Mensah, K. (1992). Dealing with international students in a multicultural era. The Journal of Academic Librarianship, 18, 214-216.

Sarkodie-Mensah, K. (1994). The international student in the US academic library. In: K. Hoover (Ed.), Diversity and multiculturalism in libraries (pp. 105-120). Greenwich, CT: JAI Press.

United States Department of Commerce. (2000). Statistical abstract of the United States. Washington: Government Printing Office. 